\title{
DEVELOPMENT OF HYPERPOLARIZING INHIBITORY POSTSYNAPTIC POTENTIALS AND HYPERPOLARIZING RESPONSE TO $\gamma$-AMINOBUTYRIC ACID IN RABBIT HIPPOCAMPUS STUDIED IN VITRO ${ }^{1}$
}

\author{
ALAN L. MUELLER, ${ }^{*}$ JEFFREY S. TAUBE, $\ddagger$ AND PHILIP A. SCHWARTZKROIN* $\ddagger^{2}$ \\ Departments of ${ }^{*}$ Neurological Surgery and $¥$ Physiology and Biophysics, University of Washington, Seattle, Washington 98195
}

Received September 9, 1983; Revised November 4, 1983; Accepted November 4, 1983

\begin{abstract}
The postnatal development of IPSPs and response to locally applied GABA were examined using intracellular recording techniques in region $\mathrm{CA} 1$ of rabbit hippocampal slices maintained in vitro. Pyramidal neurons in slices from mature rabbits demonstrated an EPSP-IPSP sequence following stimulation of stratum radiatum. In these same slices, pressure application of GABA into stratum pyramidale and stratum radiatum produced membrane hyperpolarization and depolarization, respectively.

Pyramidal neurons in slices from immature rabbits (age 6 to 10 days) responded differently. Stimulation of stratum radiatum produced a prolonged depolarizing postsynaptic potential; few IPSPs were observed. Ejection of GABA into either stratum pyramidale or stratum radiatum evoked a depolarizing response.

The GABA agonist, 4,5,6,7-tetrahydroisoxazolo [5,4-c] pyridine-3-ol (THIP), which has been reported to activate "hyperpolarizing" GABA receptors selectively, primarily produced membrane hyperpolarization when applied to the somata of mature neurons, but it evoked a depolarization when applied to immature neurons. Bicuculline, a GABA antagonist which may have a preferential selectivity for "depolarizing" GABA receptors, was somewhat more efficacious (at $50 \mu \mathrm{M}$ concentration) at antagonizing GABA-evoked depolarization in immature cells than GABA-evoked hyperpolarization in mature cells. This same concentration of bicuculline partially antagonized IPSPs in mature cells, and it markedly potentiated depolarizing PSPs in immature cells. Taken together, these results suggest that the late development of synaptic inhibition in rabbit hippocampus is due, at least in part, to an immaturity in the GABAergic system.
\end{abstract}

Although the hippocampus has been the subject of numerous electrophysiological studies, only a few such studies have concerned themselves with the development of this brain region (Dzidzishvili and Kvirkvelia, 1968;

\footnotetext{
${ }^{1}$ This work was supported by National Institutes of Health, National Institute of Neurological and Communicative Disorders and Stroke Grants NS 15317, NS 00413, and NS 17111. A. L. M. is the recipient of a National Research Service Award Postdoctoral Fellowship (NS 07012). J. S. T. is a predoctoral trainee in the Departments of Psychology, and Physiology and Biophysics (GM 07108). P. A. S. is an affiliate of the Child Development and Mental Retardation Center, University of Washington. We wish to thank Mr. Randall M. Chesnut for his help in acquiring some of the data, and Linda D. Artman for her help in preparation of the figures.

${ }^{2}$ To whom correspondence should be addressed, at Department of Neurological Surgery RI-20, University of Washington, Seattle, WA 98195.
}

Purpura et al., 1968; Schwartzkroin and Altschuler, 1977; Schwartzkroin, 1982; Harris and Teyler, 1983). One question which has arisen from these studies concerns the time course of the development of inhibitory synaptic activity. Intracellular experiments on kitten hippocampus in vivo suggested that inhibition was the predominant form of synaptic activity early in development (Purpura et al., 1968). In vitro slice studies, on the other hand, suggested that excitatory synaptic events were more common in hippocampal tissue from young kittens, and that inhibitory synaptic activity was fairly late in developing (Schwartzkroin and Altschuler, 1977). This latter finding has recently been demonstrated in slices of rabbit (Schwartzkroin, 1982) and rat (Dunwiddie, 1981; Harris and Teyler, 1983) hippocampus.

A large body of evidence exists to support the idea that synaptic inhibition in the hippocampus is mediated by GABA (for review, see Storm-Mathisen, 1977). GABA is 
proposed to mediate both feedback (Kandel et al., 1961; Andersen et al., 1964a, b) and dendritic feedforward inhibition (Fujita, 1979; Alger and Nicoll, 1982a). In addition to the typical hyperpolarizing action, GABA has recently been reported to evoke a depolarization when applied selectively to the dendritic tree of mature CA1 pyramidal neurons (Alger and Nicoll, 1979, 1982b; Andersen et al., 1980; Djørup et al., 1981; Thalmann et al., 1981). The ionic mechanism of this depolarization has not yet been fully elucidated but appears to involve a cation (sodium or calcium) as well as chloride. In addition, somatic hyperpolarizing and dendritic depolarizing responses to locally applied GABA may be mediated via two pharmacologically distinct GABA receptors (Alger and Nicoll, 1982b).

Biochemical and pharmacological studies examining a number of indices of GABAergic transmission (GABA receptor binding, high affinity GABA uptake, GABA levels, glutamic acid decarboxylase (GAD) localization) suggest that the GABAergic system in rats is not fully developed at birth, but that it matures to the adult state within a few wecks (Coyle and Enna, 1976; Palacios et al., 1979; Aldinio et al., 1980; Wong and McGeer, 1981; Skerrit and Johnston, 1982). In addition, morphological studies have demonstrated a paucity of symmetric, axosomatic (presumably inhibitory) synapses in immature hippocampus (Schwartz et al., 1968; Schwartzkroin et al., 1982). It should be noted, however, that interneuron cell types have been demonstrated in immature hippocampus, both morphologically (Purpura and Pappas, 1968; Schwartzkroin et al., 1982) and electrophysiologically (Schwartzkroin, 1982).

Based upon these findings, we hypothesized that an immaturity in the GABAergic system might underlie the late development of hyperpolarizing inhibitory synaptic activity in the hippocampus. To test this hypothesis, GABA was locally applied to the somata and dendrites of CA1 pyramidal neurons in slices from mature and immature rabbits. The actions of the GABA agonist, (4,5,6,7-tetrahydroisoxazolo [5,4-c] pyridine-3-ol (THIP), which has been reported to activate "hyperpolarizing" GABA receptors selectively (Alger and Nicoll, 1982b), and the GABA antagonist, bicuculline, which was reported to antagonize "depolarizing" GABA receptors selectively (Alger and Nicoll, 1982b), were also examined in order to gain some insight into the cellular mechanisms of the development of the hippocampal GABAergic system. Some of these findings have been reported previously (Chestnut and Schwartzkroin, 1982; Mueller et al., 1983).

\section{Materials and Methods}

Experiments were performed on hippocampal tissue from New Zealand white rabbits using the in vitro slice technique, as described previously (Schwartzkroin, 1982). Electrophysiological data were collected from immature (age 6 to 10 days), mature (age 1 month), and "adolescent" (age 11 to 18 days) rabbits. Rabbits were decapitated, the brain was rapidly removed, and the hippocampus was dissected free. The dissection was greatly facilitated by keeping the tissue cold $\left(10^{\circ} \mathrm{C}\right)$ dur- ing the procedure. The dissected hippocampus was laid out on the stage of a tissue chopper (Sorvall TC-2) and $500-\mu \mathrm{m}$ transverse slices were cut from the middle third of the structure. Slices were immediately transferred to an incubation chamber where they lay on a nylon mesh grid at a fluid-gas interface. The bathing medium, which contacted the slices at their undersurfaces, was composed of $124 \mathrm{~mm} \mathrm{NaCl}, 5 \mathrm{mM} \mathrm{KCl}, 1.25 \mathrm{mM} \mathrm{NaH}_{2} \mathrm{PO}_{4}, 2 \mathrm{mM}$ $\mathrm{MgSO}_{4}, 2 \mathrm{mM} \mathrm{CaCl}, 26 \mathrm{~mm} \mathrm{NaHCO}$, and $10 \mathrm{~mm}$ dextrose. Slices and medium were maintained at $35 \pm$ $0.5^{\circ} \mathrm{C}$ with a feedback control system. Bathing medium was oxygenated with $95 \% \quad \mathrm{O}_{2} / 5 \% \quad \mathrm{CO}_{2}$, and the atmosphere above the slices was kept warm, moist, and oxygenated.

Intracellular recordings from CA1 pyramidal neurons were obtained with micropipettes filled with $4 \mathrm{M}$ potassium acetate plus $0.01 \mathrm{M} \mathrm{KCl}$. Electrode resistance was approximately 80 to 100 megohms. Cell stimulation was carried out using both intracellular current injection (100-msec pulses of $0.5 \mathrm{nA}$ depolarizing current through the recording electrode via a bridge circuit) and extracellular stimulation (bipolar tungsten electrodes) of afferent pathways in stratum radiatum. Cellular input resistance $\left(R_{\text {in }}\right)$ was estimated by injecting hyperpolarizing current pulses $(0.5 \mathrm{nA}, 100 \mathrm{msec})$ into the cell and measuring the resulting steady-state voltage deflection from resting membrane potential. Membrane potential was altered by injection of either depolarizing or hype:polarizing DC current into the cell through the recording electrode; bridge balance was continuously monitored and adjusted as necessary during this procedure. Data were displayed on an oscilloscope and stored on magnetic tape for later analysis.

GABA (or THIP) was applied locally into stratum pyramidale or stratum radiatum by pressure ejection. The following parameters were routinely used for drug ejection: $1 \mathrm{~mm}$ GABA (or THIP) in normal saline, $\mathrm{pH}$ 6.5; drug pipette resistance approximately 30 megohms; applied pressure $30 \mathrm{psi}$ (approximately $2 \mathrm{~kg} / \mathrm{cm}^{2}$ ); pulse duration approximately $75 \mathrm{msec}$; interpulse interval 10 to $30 \mathrm{sec}$. GABA and bicuculline methiodide were obtained from Sigma Chemical Co. and Pierce Chemical Co., respectively. THIP was generously supplied by Dr. P. Krogsgaard-Larsen. Discrete "hot-spots" of drug sensitivity were found, both in stratum pyramidale and stratum radiatum; movement of the drug pipette by as little as 5 to $10 \mu \mathrm{m}$ could dramatically alter the amplitude of the drug response. Control ejections of normal saline alone had no effects.

The response to drug (peak change in membrane potential) was determined at a number of different levels of membrane potential for each cell. These points wcre plotted, and a line relating peak drug response amplitude to membrane potential was then fitted to the points by the method of least squares. A correlation coefficient $(r)$ and a slope were determined for each line. The reversal potential $\left(E_{\text {rev }}\right)$ of the drug response, and the drug response at an arbitrary membrane potential of $-60 \mathrm{mV}$ (near rest) were obtained from the plotted line (either directly or by extrapolation, when necessary). Each of these values was then averaged across cells to determine mean values ( $\pm \mathrm{SEM}$ ) for mature, immature, and adoles- 
cent tissue. A similar procedure was used to analyze postsynaptic potentials (measured at 20 to $30 \mathrm{msec}$ after stimulus). Statistical analysis was by means of the Student's $t$ test (unpaired, two-tailed), with the Bonferroni correction for multiple $t$ tests made where appropriate (Wallenstein et al., 1980).

In addition to alterations in membrane potential, drugevoked changes in $R_{\text {in }}$ were noted as well. Input resistance was estimated prior to and following drug ejection; the maximum percent decrease in $R_{\text {in }}$ produced by drug was then determined for each cell.

\section{Results}

Characteristics of mature and immature CA1 pyramidal neurons. Successful impalements and recordings were obtained from 29 mature CA1 pyramidal neurons (in 21 slices from 19 rabbits), 44 immature CA1 pyramidal neurons (in 34 slices from 23 rabbits), and 8 adolescent CA1 pyramidal neurons (in 8 slices from 7 rabbits). In general, immature cells had lower (more depolarized) resting potentials, smaller action potentials, and higher input resistances than did mature cells (Table I). Adolescent cells had values intermediate between those for mature and immature cells (Table I).

Hippocampal CA1 pyramidal cells demonstrate anomalous inward rectification (Hotson et al., 1979), such that $R_{\text {in }}$ increases as the cell is depolarized. As $R_{\text {in }}$ was estimated at only one level of membrane potential (rest) in the present study, it appeared as if the higher values of
$R_{\text {in }}$ in immature neurons might be due to their lower (more depolarized) resting membrane potentials. This was not the case, however; $R_{\text {in }}$ is not correlated with resting membrane potential $(r=0.18, n=80, p>0.05)$.

Immature neurons often demonstrated spontaneous depolarizations of up to $30 \mathrm{mV}$ amplitude and 30 to 60 sec duration. These "spreading depression" episodes (Leão, 1972; Schwartzkroin and Haglund, 1982) were rarely seen in mature neurons, and only then in the presence of bicuculline.

Postsynaptic potentials. Stimulation of afferent fibers in stratum radiatum evoked an EPSP-IPSP sequence in mature CA1 pyramidal neurons (Fig. 1). In most cases,

TABLE I

Cellular properties of mature, immature, and adolescent CA1 pyramidal neurons

Resting membrane potential, input resistance, and action potential amplitude were monitored in mature (age 1 month; $n=29$ ), immature (age 6 to 10 days; $n=44$ ), and adolescent (age 11 to 16 days; $n=8$ ) CA1 pyramidal neurons.

\begin{tabular}{lccc}
\hline & Mature & Immature & Adolescent \\
\hline $\begin{array}{l}\text { Resting membrane potential } \\
(\mathrm{mV})\end{array}$ & $-59.0 \pm 1.6$ & $-53.1 \pm 1.5^{a}$ & $-57.8 \pm 3.5$ \\
Input resistance (megohms) & $36.8 \pm 2.2$ & $52.2 \pm 3.5^{a}$ & $44.8 \pm 5.8$ \\
Action potential amplitude & $60.2 \pm 1.9$ & $54.0 \pm 2.3^{a}$ & $57.0 \pm 4.4$
\end{tabular}

$(\mathrm{mV})$

${ }^{a} p<0.05$ compared to mature. Each value represents the mean \pm SEM.
GABA

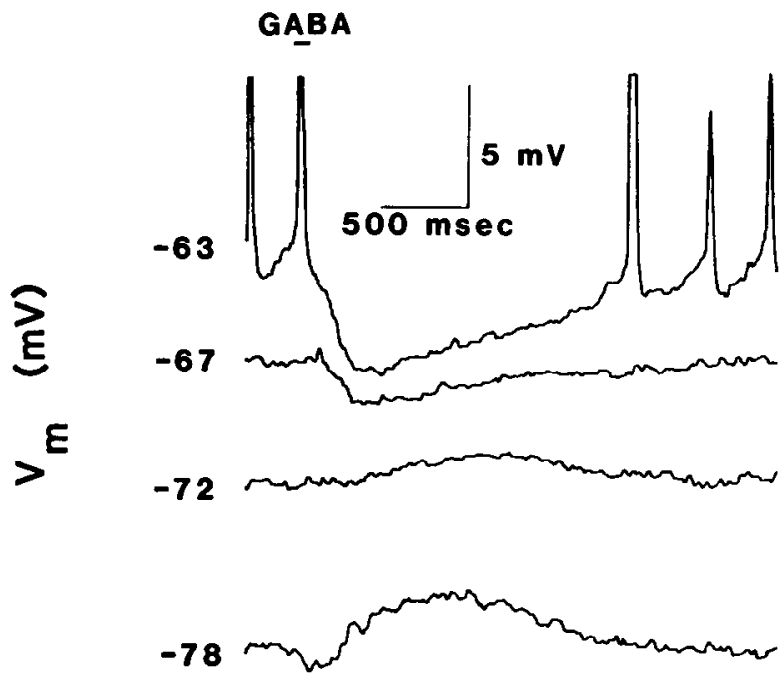

PSP

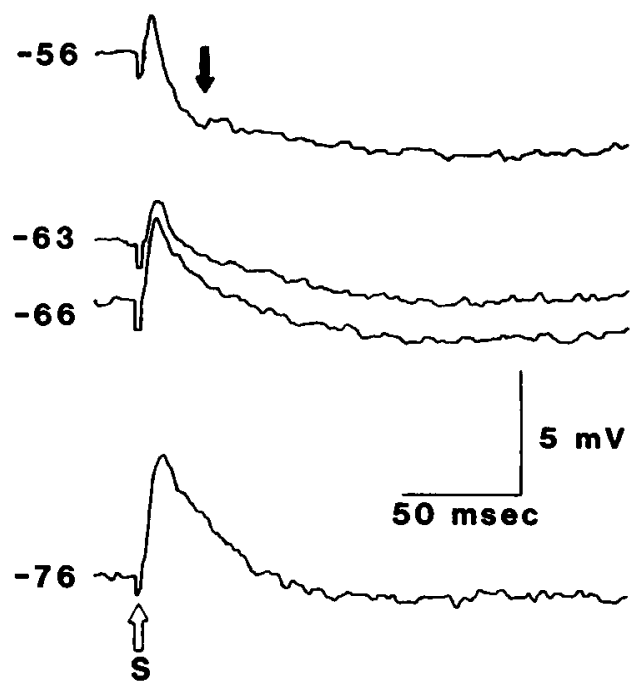

Figure 1. Responses to GABA and orthodromic stimulation at different levels of membrane potential in a mature CA1 pyramidal neuron. GABA was applied locally to the soma of this neuron by pressure ejection (time and duration of ejection indicated by the dark bar). The numbers refer to membrane potential ( $V_{m}$, in millivolts). The reversal potential for the GABAevoked hyperpolarization in this cell was approximately $-70 \mathrm{mV}$. Orthodromic stimulation of stratum radiatum afferents produced an EPSP-IPSP sequence (stimulation indicated by open arrow). The IPSP, measured at 25 msec poststimulus (solid arrow), reversed at approximately $-62 \mathrm{mV}$. Resting membrane potential was $-67 \mathrm{mV}$. The more positive $E_{\text {rev }}$ for the IPSP (compared to the GABA response) is probably due to the "contamination" of the IPSP (at a 25-msec latency) by the tail of the EPSP. Note different time scales for GABA and PSP records. The traces were "smoothed" by a computer averaging program; spikes are, therefore, distorted and are further truncated by the penwriter. 
GABA

GABA

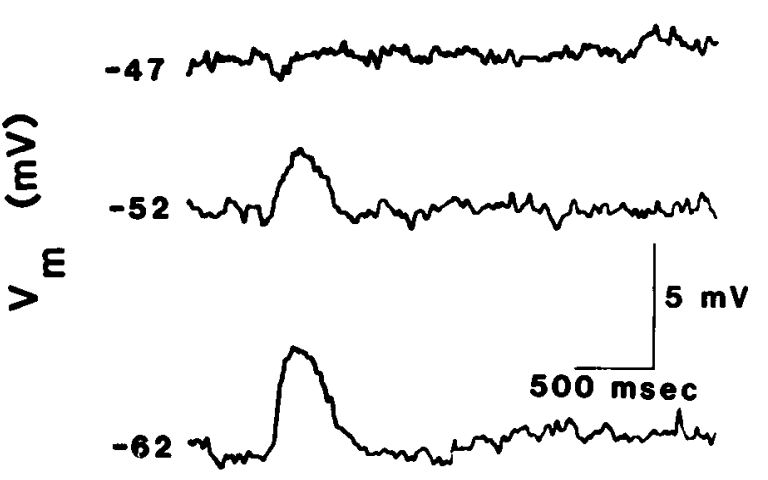

PSP

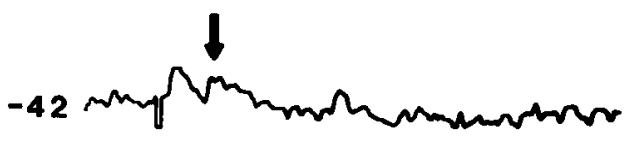

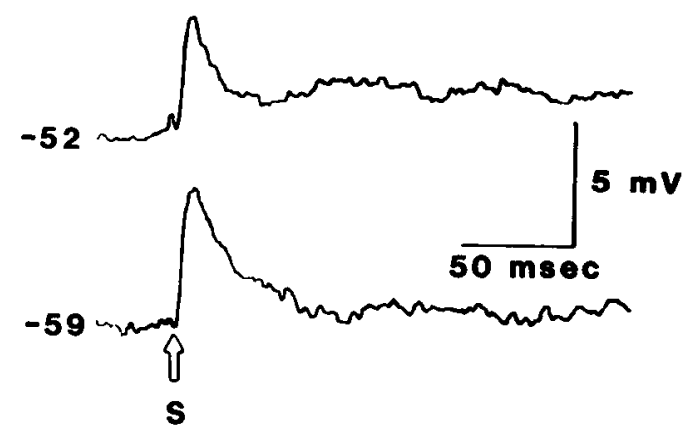

Figure 2. Responses to GABA and orthodromic stimulation at different levels of membrane potential in an immature CA1 pyramidal neuron. GABA was applied locally to the soma of this neuron by pressure ejection (time and duration of ejection indicated by the dark bar). The numbers refer to the membrane potential ( $V_{m}$, in millivolts). In this cell, GABA evoked a depolarization which reversed at approximately $-47 \mathrm{mV}$. Orthodromic stimulation in stratum radiatum (open arrow) produced a longer lasting depolarizing PSP which reversed at approximately $-42 \mathrm{mV}$ (measured at 25 msec poststimulus). Resting membrane potential was $-52 \mathrm{mV}$. Note different time scales for GABA and PSP records.

stimulus intensity was adjusted such that the EPSP was subthreshold for spike initiation. The amplitude of the IPSP (measured at 20 to $30 \mathrm{msec}$ poststimulus) was dependent on the level of membrane polarization, with a mean reversal potential of $-66.8 \pm 4.5 \mathrm{mV}(n=13)$.

A different type of synaptic response was seen in immature neurons. In this case, afferent stimulation gave rise to a long-lasting depolarizing postsynaptic potential (PSP) with no sign of an IPSP (Fig. 2). This PSP was capable of evoking action potential discharge. The amplitude of this response (also measured at 20 to $30 \mathrm{msec}$ poststimulus) was sensitive to current injection; the mean reversal potential, obtained by extrapolation, was $-36.4 \pm 5.4 \mathrm{mV}$ ( $n=18 ; p<0.05$ compared to mature). As previously reported (Schwartzkroin, 1982), IPSP activity was seen to develop in the adolescent CA1 pyramidal neurons at about age 14 to 16 days. Taking all age groups into consideration, there was a trend toward a more negative reversal potential for the PSP response as the age of the animal increased.

Response to GABA. Pressure ejection of minute amounts of GABA into stratum pyramidale near (10 to $20 \mu \mathrm{m})$ the recording electrode produced a hyperpolarization in 8 of 10 mature CA1 pyramidal neurons (Fig. 1) and a depolarization or a biphasic hyperpolarizationdepolarization in the remaining cells. The GABA-evoked hyperpolarization had a mean amplitude of $-3.5 \pm 1.4$ $\mathrm{mV}$ at a membrane potential of $-60 \mathrm{mV}$ and a mean duration at half-maximum of $703 \pm 145 \mathrm{msec}$. The mean reversal potential of this response, $-70.9 \pm 3.9 \mathrm{mV}$, was not statistically different from the reversal potential of the IPSP in these mature cells $(p>0.05)$. GABA applied to a spontaneously firing cell could depress action potential discharge rate. The GABA-evoked hyperpolarization was accompanied by a maximal decrease in $R_{\text {in }}$ of $51 \pm$ $9 \%$.

Application of GABA to the somata of immature CA1 pyramidal neurons produced a depolarization in 25 of 26 cells (Fig. 2) and a biphasic hyperpolarization-depolarization in the remaining cell. The depolarization had a mean amplitude of $+4.2 \pm 1.1 \mathrm{mV}$ at a membrane potential of $-60 \mathrm{mV}$ and a mean duration at half-maximum of $683 \pm 82 \mathrm{msec}$. The mean reversal potential of this depolarization was $-46.0 \pm 3.4 \mathrm{mV}(p<0.05$ compared to the reversal potential of the hyperpolarization in mature cells). A maximum reduction in $R_{\text {in }}$ of $32 \pm 7 \%$ accompanied this response. Both increases and decreases in spontaneous action potential discharge rate were observed. In general, the reversal potential of the somatic GABA response became more negative as the age of the animal increased. GABA applied to the somata of adolescent cells typically evoked a biphasic hyperpolarizingdepolarizing response (five cells).

Application of GABA into the apical dendrites (150 to $250 \mu \mathrm{m}$ from the recording electrode) produced a depolarization of CA1 pyramidal neurons of all ages $(n=9)$. This depolarizing response had a mean amplitude of +4.1 $\pm 1.0 \mathrm{mV}$ at a membrane potential of $-60 \mathrm{mV}$ and a duration at half-maximum of $927 \pm 222 \mathrm{msec}$. This dendritic response to GABA proved to be difficult to reverse; a mean reversal potential of $-34.0 \pm 6.3 \mathrm{mV}$ was extrapolated from the line relating drug response amplitude to membrane potential. The reversal potential of this response did not appear to be correlated with the age of the animal. A decrease in $R_{\text {in }}$ of $30 \pm 8 \%$ accompanied this response.

Response to THIP. The GABA analogue, THIP, was recently reported to have a relatively greater affinity for 
"hypcrpolarizing" than for "depolarizing" GABA receptors (Alger and Nicoll, 1982b). Therefore, we examined the actions of this drug on mature and immature CA1 pyramidal neurons in an effort to determine whether different GABA receptor subtypes might mediate the opposing actions of GABA in mature and immature cells.

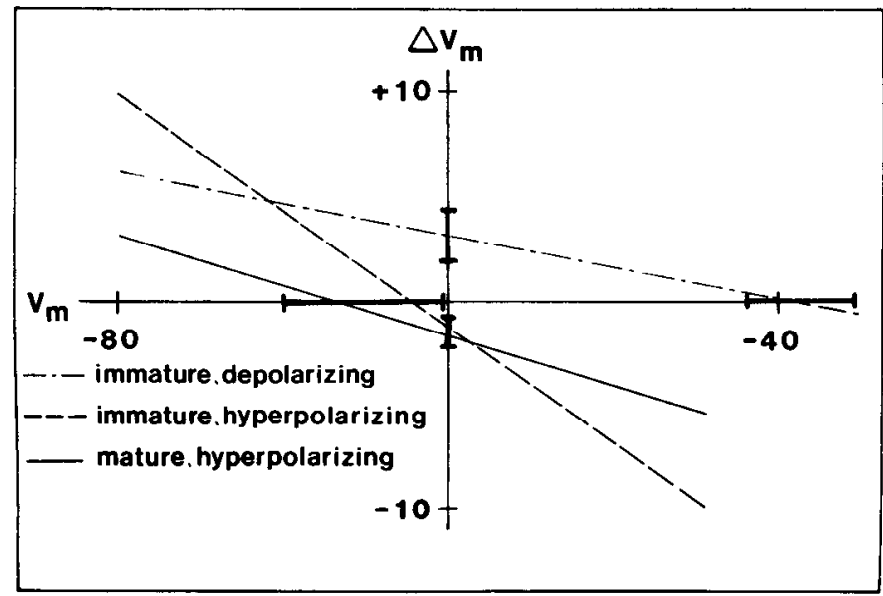

Figure 3. Mean responses $( \pm \mathrm{SEM})$ to $\mathrm{THIP}\left(\Delta V_{m}\right)$ as a function of membrane potential $\left(V_{m}\right)$ in a number of mature and immature CA1 pyramidal neurons. THIP applied to the somata of mature neurons $(-; n=10)$ evoked a hyperpolarizing response at $-60 \mathrm{mV}\left(\Delta V_{m}=-1.6 \pm 0.5 \mathrm{mV}\right)$ which reversed at $-67.2 \pm 2.3 \mathrm{mV}$. THIP applied to the somata of immature neurons evoked both depolarizing $(-\cdot-; n=8)$ and hyperpolarizing $(--; n=2)$ responses. The depolarizing $\left(\Delta V_{m}\right.$ at $-60 \mathrm{mV}$ $=+3.2 \pm 1.2 \mathrm{mV})$ and hyperpolarizing $\left(\Delta V_{m}\right.$ at $-60 \mathrm{mV}=-1.1$ $\pm 0.2 \mathrm{mV}$ ) responses reversed at $-39.0 \pm 3.0 \mathrm{mV}$ (obtained by extrapolation) and $-62.1 \pm 1.5 \mathrm{mV}$, respectively. Ordinate, response to THIP (change in membrane potential, in millivolts). Abscissa, membrane potential (in millivolts).
In slices from mature rabbits, pressure ejection of THIP into stratum pyramidale resulted in a hyperpolarization of 10 of 14 neurons, a depolarization of 2 of 14 neurons, and a biphasic hyperpolarization-depolarization in 2 of 14 neurons. A hyperpolarizing response to somatically applied THIP has been reported previously (Alger and Nicoll, 1982b). In the present study, the hyperpolarizing response to THIP demonstrated a mean reversal potential of $-67.2 \pm 2.3 \mathrm{mV}$ (Fig. 3) and was accompanied by a maximum reduction in $R_{\text {in }}$ of $38 \pm 4 \%$. This THIP. evoked hyperpolarization had a long time course (duration at half-maximum $=3145 \pm 846 \mathrm{msec}$ ), presumably due to the fact that THIP is not a substrate for the high affinity neuronal uptake process for GABA (KrogsgaardLarsen and Johnston, 1978).

In contrast, somatic application of THIP in slices from immature rabbits usually produced a depolarization $(8$ of 14 cells); occasionally a biphasic hyperpolarization-depolarization ( 4 of 14 cells) or a pure hyperpolarizing response ( 2 of 14 cells) was seen. The depolarizing and hyperpolarizing responses to somatic THIP had mean reversal potentials of $-39.0 \pm 3.0 \mathrm{mV}$ and $-62.5 \pm 1.5$ $\mathrm{mV}$, respectively (Fig. 3). Actions of THIP in these immature cells were prolonged, with a duration at halfmaximum of $6961 \pm 1899 \mathrm{msec}$, and were associated with a maximal decrease in $R_{\text {in }}$ of $46 \pm 5 \%$.

Interactions of GABA and bicuculline. Previous reports have suggested that the GABA antagonist, bicuculline methiodide (BMI), is approximately two orders of magnitude more selective at antagonizing "depolarizing" than "hyperpolarizing" GABA responses (Alger and Nicoll, 1982b). Therefore, the actions of BMI were examined on stimulus-evoked PSPs and on depolarizing responses to somatic GABA application in immature and hyperpolarizing responses to somatic GABA application in mature $\mathrm{CA} 1$ pyramidal neurons.
Control

GABA

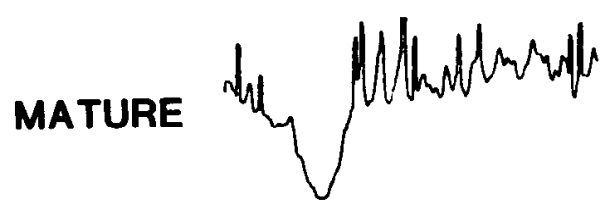

GABA

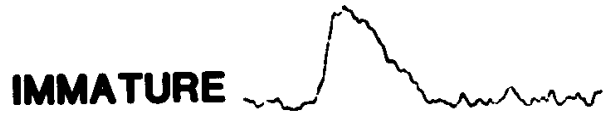

$50 \mu \mathrm{M}$ BMI

GABA

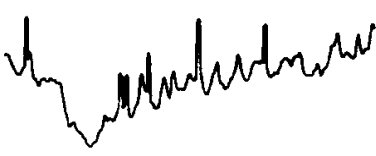

GABA

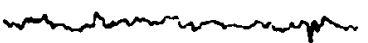

Recovery

GABA

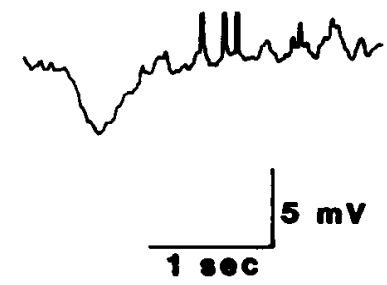

GABA

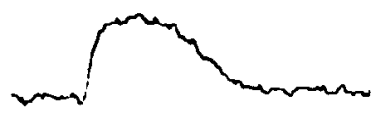

Figure 4. Actions of bicuculline (BMI) on GABA-evoked responses in a mature and an immature CA1 pyramidal neuron. Application of GABA ( $100-\mathrm{msec}$ pulse once every $20 \mathrm{sec}$, indicated by dark bar) to the somatic regions of these neurons produced consistent and reproducible changes in membrane potential. The bathing medium was then switched (for 20 min) to one containing $50 \mu \mathrm{M}$ BMI. The depolarizing GABA response in the immature cell was completely antagonized by this concentration of BMI, whereas the hyperpolarizing GABA response in the mature cell was relatively unaffected. Recovery of the depolarizing response was seen $20 \mathrm{~min}$ after switching back to control medium. Each trace is the average of eight separate sweeps; spikes are, therefore, distorted and are further truncated by the penwriter. Resting potentials were $-65 \mathrm{mV}$ (mature) and $-59 \mathrm{mV}$ (immature). 

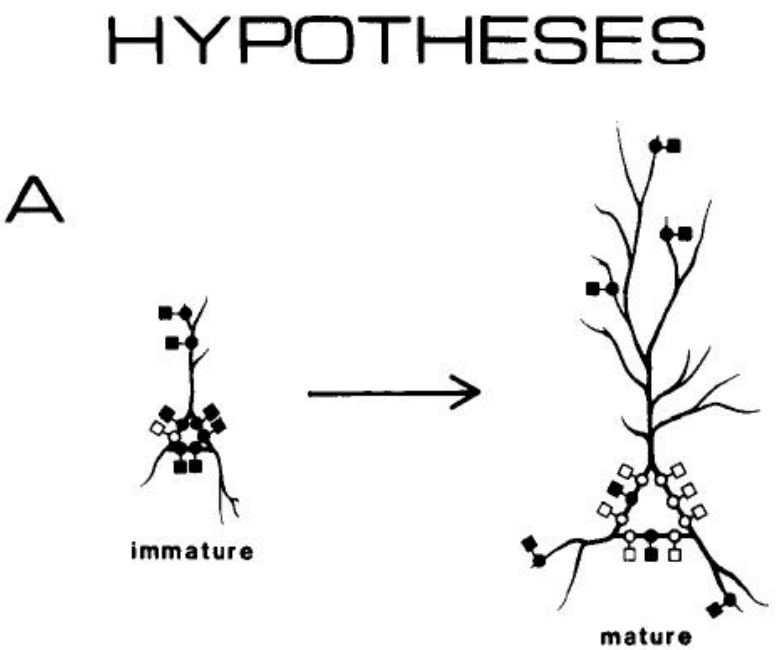

- depolarizing receptor-ionophore complex

DO hyperpolarizing receptor-ionophore complex

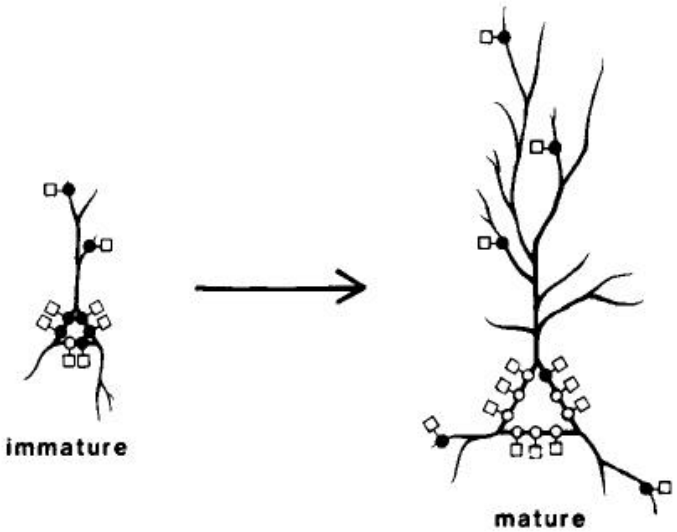

D- GABA receptor coupled to depolarizing ionophore

П- GABA receptor coupled to hyperpolarizing ionophore

Figure 5. Schematic diagrams illustrating two hypotheses concerning the development of GABAergic inhibition in rabbit hippocampus. Hypothesis A: Two GABA receptors with different ionophores. In immature tissue, "depolarizing" GABA receptors, coupled to "depolarizing" ionophores (permeable to sodium and/or calcium in addition to chloride), predominate and are found over the entire surface of the CA1 pyramidal neuron. A few "hyperpolarizing" GABA receptors, coupled to chloride ionophores, are located on the soma of this neuron. In mature tissue, the "hyperpolarizing" GABA receptor predominates on the somatic surface of the cell, while the "depolarizing" receptor remains the major receptor type in the dendrites. The appearance of hyperpolarizing IPSPs and of hyperpolarizing responses to somatic GABA in CA1 pyramidal neurons depends on the development of "hyperpolarizing" GABA receptor-chloride ionophore complexes in the somatic membrane of these cells. Hypothesis B: One GABA receptor type and two ionophores. In immature tissue, one GABA receptor type is found over the entire surface of the neuron. This receptor is coupled in the dendritic and somatic membranes primarily to "depolarizing" ionophores which gate for chloride, and sodium and/or calcium. The ionophore in the somatic membrane "matures" such that it is permeable only to chloride in the mature neuron, and so becomes a "hyperpolarizing" ionophore. The dendritic iono-
Addition of $50 \mu \mathrm{M}$ BMI to the perfusion medium resulted in an increase in the excitability of both mature and immature slices; spontaneous burst discharges were frequently observed. This concentration of BMI produced an antagonism of GABA-evoked depolarizing responses in seven of nine immature CA1 pyramidal neurons; in one cell, in fact, the depolarizing response was reversed such that the same "dose" of GABA evoked a hyperpolarization rather than a depolarization. Only two of seven GABA-evoked hyperpolarizations in mature neurons were antagonized by this same concentration of BMI ( $\chi^{2}=3.8740 ; p<0.05$; Fig. 4$)$. In addition, this concentration of BMI produced a modest antagonism of the IPSP in three of six mature pyramidal neurons and a marked potentiation of both the amplitude and the duration of the depolarizing PSP in six of six immature cells.

\section{Discussion}

The primary finding of the present study is that the GABAergic inhibitory system in the rabbit hippocampus does not appear to be fully developed at birth, but matures slowly, reaching the adult state at about 2 to 3 weeks postnatal. Specifically, immature CA1 pyramidal neurons demonstrate a prolonged depolarizing PSP in response to stratum radiatum stimulation, and they respond to local somatic application of GABA with a depolarization. In mature pyramidal neurons, on the other hand, stratum radiatum stimulation elicits an EPSP-IPSP sequence and somatic GABA application evokes a membrane hyperpolarization. Our results are consistent with those previously reported for mature CA1 hippocampal pyramidal cells, in that local application of GABA into stratum radiatum and stratum pyramidale produces a depolarization and a hyperpolarization, respectively (Alger and Nicoll, 1979, 1982b; Andersen et al., 1980; Djørup et al., 1981; Thalmann et al., 1981).

The cellular mechanisms underlying the opposing hyperpolarizing and depolarizing actions of GABA have not yet been fully elucidated. Based on our findings, two plausible hypotheses can be stated (Fig. 5). First, these two responses might be mediated by two separate GABA receptor subtypes, each coupled to its own ionophore (Fig. 5A; Alger and Nicoll, 1982b; see also Brown et al., 1981). In immature tissue, "depolarizing" GABA receptors are coupled to ionophores permeable not only to chloride but to sodium and/or calcium as well; these receptor-ionophore complexes are found over the entire surface of the CA1 pyramidal neuron. A few "hyperpolarizing" GABA receptors, coupled to chloride ionophores, are located on the somatic surface of these immature cells. As the hippocampus matures, the "hyperpolarizing" GABA receptor-ionophore complex becomes more numerous, primarily in the somatic membrane, where it develops in association with symmetric "inhib-

phore, however, remains one of the "depolarizing" type. The development of somatic "hyperpolarizing" ionophores selective for chloride therefore underlies the appearance of hyperpolarizing IPSPs and of hyperpolarizing responses to GABA in these neurons. 
itory" synapses. The majority of receptor-ionophore complexes in the dendritic tree remain of the "depolarizing" type. As there exist only a few symmetric "inhibitory" synapses on immature CA1 pyramidal cells and in the dendrites of mature neurons (Schwartz et al., 1968; Schwartzkroin et al., 1982), these "depolarizing" receptor-ionophore complexes perhaps should be labeled as "extrasynaptic" (Brown et al., 1981). The appearance of hyperpolarizing IPSPs and of hyperpolarizing responses to GABA applied to the somata would depend on the development of the "hyperpolarizing" GABA receptorionophore complexes in the somatic membrane of these CA1 pyramidal neurons.

A second possible explanation for the dual actions of GABA is that a single type of GABA receptor is coupled to functionally different ionophores (Fig. $5 B$ ). In the mature cell, the somatic GABA receptor is coupled to a chloride channel such that receptor activation leads to a membrane hyperpolarization. The ionophore in the immature cell (and in the dendritic membrane of the mature cell) is permeable to sodium and/or calcium as well, such that receptor activation leads to a membrane depolarization. The two functionally different ionophores in mature and immature neurons may be physically distinct, separate species; alternatively, the ionophore in immature neurons may be an immature form of the one found in mature cells. In either case, the appearance of hyperpolarizing IPSPs and of a hyperpolarizing response to somatic GABA application would depend on the development of the mature "hyperpolarizing" ionophore.

Although our data are not entirely conclusive, they do tend to favor the first hypothesis, that of two different GABA receptor subtypes. Specifically, the GABA receptor antagonist, BMI, was found to be significantly more effective (at a concentration of $50 \mu \mathrm{M}$ ) at antagonizing GABA-evoked depolarizations in immature cells than GABA-evoked hyperpolarizations in mature cells. As $\mathrm{BMI}$ is believed to bind to the GABA receptor rather than to the ionophore (Olsen, 1982), this differential effect of BMI would support the existence of different receptor types rather than different ionophores.

The concept of multiple GABA receptor subtypes also is supported by a variety of studies in the literature. High and low affinity GABA receptor sites have been identified in receptor binding studies (Enna and Snyder, 1975; Beaumont et al., 1978; Olsen et al., 1981). In addition, a novel subtype of GABA receptor, the $\mathrm{GABA}_{\mathrm{B}}$ or baclofen-sensitive site, has been described (Hill and Bowery, 1981). It is unclear at present whether any of these GABA receptor subtypes correspond to either the "depolarizing" or "hyperpolarizing" GABA receptors; however, THIP has been suggested to bind selectively and with high affinity to a discrete population of GABA receptors (Falch and Krogsgaard-Larsen, 1982). Finally, it is noteworthy that Obata and his colleagues (1978) proposed the existence of two types of GABA receptors in developing embryonic chick spinal neurons in culture.

Our results suggest that the opposing actions of GABA are not due to different chloride distributions (i.e., a much higher intracellular chloride concentration in immature neurons and in the dendrites of mature neurons). First, application of GABA and THIP to a single discrete site was observed to produce a biphasic response (hyperpolarization-depolarization) in some mature and immature CA1 pyramidal neurons. Second, a GABA-evoked depolarization in one immature neuron was reversed to a hyperpolarizing response by BMI. Third, previous results have demonstrated that dendritic applications of GABA and THIP are capable of producing a hyperpolarizing response in mature CA1 pyramidal cells (Alger and Nicoll, 1982b). Fourth, application of GABA to cultured spinal neurons from 6-day and 10-day chick embryos elicits depolarizations and hyperpolarizations, respectively; however, no significant differences in intracellular chloride concentrations were seen in neurons from 6-day versus 10-day embryos (Obata et al., 1978).

The functional significance of the depolarizing somatic response to GABA in immature neurons is presently unclear. Previous studies suggested that some component of the depolarizing PSP evoked in immature CA1 neurons was bicuculline-sensitive (and, therefore, presumably GABA-mediated; Schwartzkroin, 1982); this finding was confirmed in the present study. It was also noted in the present study that bicuculline treatment resulted in an apparent "hyperexcitability" of immature as well as mature slices, manifested primarily as spontaneous bursting activity. Therefore, it would appear that some type of GABA-mediated inhibition is present even in these immature slices. It is not possible at present to state whether this inhibition is mediated by the more numerous "depolarizing" GABA receptors (via a conductance increase mechanism) or the relatively few "hyperpolarizing" GABA receptors present on these immature neurons. However, it should be noted that a reduction in input resistance of approximately $40 \%$ was associated with the somatically evoked depolarizing response to GABA in these cells; a functional inhibition could result from this "shunting" effect regardless of the sign of the change in membrane potential.

The enhanced sensitivity of immature central nervous system neurons to seizure activity has been recognized for years. However, the basic mechanism(s) underlying this observation remains unknown. As the hippocampus is especially prone to epileptiform activity, many studies have concerned themselves with this brain region. Our studies show that the hippocampal GABAergic system does not suddenly appear in its mature form but changes as a function of neuronal maturity. Therefore, these findings provide a possible clue as to the susceptibility of immature CNS tissue to seizure activity.

\section{References}

Aldinio, C., M. A. Balzano, and G. Toffano (1980) Ontogenic development of GABA recognition sites in different brain areas. Pharmacol. Res. Commun. 12: 495-500.

Alger, B. E., and R. A. Nicoll (1979) GABA-mediated biphasic inhibitory responses in hippocampus. Nature $281: 315-317$.

Alger, B. E., and R. A. Nicoll (1982a) Feed-forward dendritic inhibition in rat hippocampal pyramidal cells studied in vitro. J. Physiol. (Lond.) 328: 105-123.

Alger, B. E., and R. A. Nicoll (1982b) Pharmacological evidence for two kinds of GABA receptors on rat hippocampal pyramidal cells studied in vitro. J. Physiol. (Lond.) 328: 125141.

Andersen, P., J. C. Eccles, and Y. Løyning (1964a) Location of 
postsynaptic inhibitory synapses on hippocampal pyramids. J. Neurophysiol. 27: 592-607.

Andersen, P., J. C. Eccles, and Y. Løyning (1964b) Pathway of postsynaptic inhibition in the hippocampus. J. Neurophysiol. 27: 608-619.

Andersen, P., R. Dingledine, L. Gjerstad, I. A. Langmoen, and A. Mosfeldt-Laursen (1980) Two different responses of hippocampal pyramidal cells to application of gamma-aminobutyric acid. J. Physiol. (Lond.) 305: 279-296.

Beaumont, K., W. S. Chilton, H. I. Yamamura, and S. J. Enna (1978) Muscimol binding in rat brain: Association with synaptic GABA receptors. Brain Res. 148: 153-162.

Brown, D. A., A. J. Higgins, S. Marsh, and T. G. Smart (1981) Actions of GABA on mammalian neurons, axons, and nerve terminals. In Amino Acid Neurotransmitters, F. V. DeFeudis and P. Mandel, eds., pp. 321-326, Raven Press, New York.

Chesnut, R. M., and P. A. Schwartzkroin (1982) Response to GABA in developing rabbit hippocampus. Soc. Neurosci. Abstr. 8: 326 .

Coyle, J. T., and S. J. Enna (1976) Neurochemical aspects of the ontogenesis of GABAergic neurons in the rat brain. Brain Res. 111: 119-133.

Djørup, A., H. Jahnsen, and A. Mosfeldt-Laursen (1981) The dendritic response to $\mathrm{GABA}$ in $\mathrm{CA} 1$ of the hippocampal slice. Brain Res. 219: 196-201.

Dunwiddie, 'I. V. (1981) Age-related differences in the in vitro rat hippocampus: Development of inhibition and the effects of hypoxia. Dev. Neurosci. 4: 165-175.

Dzidzishvili, N. N., and L. R. Kvirkvelia (1968) Electrophysiological signs of hippocampal development in ontogenesis. Prog. Brain Res. 22: 414-426.

Enna, S. J., and S. H. Snyder (1975) Properties of gammaaminobutyric (GABA) receptor hinding in rat brain synaptic membrane fractions. Brain Res. 100: 81-97.

Falch, E., and P. Krogsgaard-Larsen (1982) The binding of the GABA agonist $\left[{ }^{3} \mathrm{H}\right]$ THIP to rat brain synaptic membranes. J.Neurochem. 38: 1123-1129.

Fujita, Y. (1979) Evidence for the existence of inhibitory postsynaptic potentials in dendrites and their functional significance in hippocampal pyramidal cells of adult rabbits. Brain Res. 175: 59-69.

Harris, K. M., and T. J. Teyler (1983) Evidence for late development of inhibition in area CA1 of the rat hippocampus. Brain Res. 268: 339-343.

Hill, D. R., and N. G. Bowery (1981) ${ }^{3} \mathrm{H}$-baclofen and ${ }^{3} \mathrm{H}-$ GABA bind to bicuculline-insensitive $\mathrm{GABA}_{\mathrm{B}}$ sites in rat brain. Nature 290: 149-152.

Hotson, J. R., D. A. Prince, and P. A. Schwartzkroin (1979) Anomalous inward rectification in hippocampal neurons. J. Neurophysiol. 42: 889-895.

Kandel, E. R., W. A. Spencer, and F. J. Brinley (1961) Electrophysiology of hippocampal neurons. I. Sequential invasion and synaptic organization. J. Neurophysiol. 24: 225-242.

Krogsgaard-Larsen, P., and G. A. R. Johnston (1978) Structureactivity studies on the inhibition of GABA binding to rat brain membranes by muscimol and related compounds. J.
Neurochem. 30: 1377-1382.

Leão, A. A. P. (1972) Spreading depression. In Experimental Models of Epilepsy-A Manual for the Laboratory Worker, D. P. Purpura, J. K. Penry, D. Tower, D. M. Woodbury, and R. Walter, eds., pp. 173-196, Raven Press, New York.

Mueller, A. L., R. M. Chesnut, and P. A. Schwartzkroin (1983) Actions of GABA in developing rabbit hippocampus: An in vitro study. Neurosci. Lett. 39: 193-198.

Obata, K., M. Oide, and H. Tanaka (1978) Excitatory and inhibitory actions of GABA and glycine on embryonic chick spinal neurons in culture. Brain Res. 144: 179-184.

Olsen, R. W. (1982) Drug interactions at the GABA receptorionophore complex. Annu. Rev. Pharmacol. Toxicol. 22: 245277.

Olsen, R. W., M. O. Bergman, P. C. Van Ness, S. C. Lummis, A. E. Watkins, C. Napias, and D. V. Greenlee (1981) Gammaaminobutyric acid receptor binding in mammalian brain: Heterogeneity of binding sites. Mol. Pharmacol. 19: 217-227.

Palacios, J. M., D. L. Niehoff, and M. J. Kuhar (1979) Ontogeny of GABA and benzodiazepine receptors: Effects of Triton X100, bromide and muscimol. Brain Res. 179: 390-395.

Purpura, D. P., and G. D. Pappas (1968) Structural characteristics of neurons in the feline hippocampus during postnatal ontogenesis. Exp. Neurol. 22: 379-393.

Purpura, D. P., S. Prelevic, and M. Santini (1968) Postsynaptic potentials and spike variations in the feline hippocampus during postnatal ontogenesis. Exp. Neurol. 22: 408-422.

Schwartz, I. R., G. D. Pappas, and D. P. Purpura (1968) Fine structure of neurons and synapses in the feline hippocampus during postnatal ontogenesis. Exp. Neurol. 22: 394-407.

Schwartzkroin, P. A. (1982) Development of rabbit hippocampus: Physiology. Dev. Brain Res. 2: 469-486.

Schwartzkroin, P. A., and R. J. Altschuler (1977) Development of kitten hippocampal neurons. Brain Res. 134: 429-444.

Schwartzkroin, P. A., and M. M. Haglund (1982) Seizure generation in hippocampal slices from immature rabbit. Soc. Neurosci. Abstr. 8: 1017.

Schwartzkroin, P. A., D. D. Kunkel, and L. H. Mathers (1982) Development of rabbit hippocampus: Anatomy. Dev. Brain Res. 2: 453-468.

Skerritt, J. H., and G. A. R. Johnston (1982) Postnatal development of GABA binding sites and their endogenous inhibitors in rat brain. Dev. Neurosci. 5: 189-197.

Storm-Mathisen, J. (1977) Localization of transmitter candidates in the brain: The hippocampal formation as a model. Prog. Neurobiol. 8: 119-181.

Thalmann, R. H., E. J. Peck, and G. F. Ayala (1981) Biphasic response of hippocampal pyramidal neurons to GABA. Neurosci. Lett. 21: 319-324.

Wallenstein, S., C. L. Zucker, and J. L. Fleiss (1980) Some statistical methods useful in circulation research. Circ. Res. 47: 1-9.

Wong, P.T.-h., and E. G. McGeer (1981) Postnatal changes of GABAergic and glutamatergic parameters. Dev. Brain Res. 1: 519-529. 